\title{
ORIGINAL RESEARCH \\ Forced into exile: the traumatising impact of rural aged care service inaccessibility
}

\author{
MA Bernoth, E Dietsch, C Davies \\ Charles Sturt University, Wagga Wagga, New South Wales, Australia
}

Submitted: 13 September 2011; Revised: 7 December 2011; Published: 13 March 2012

Bernoth MA, Dietsch E, Davies C

Forced into exile: the traumatising impact of rural aged care service inaccessibility

Rural and Remote Health 12: 1924. (Online) 2012

Available: http://www.rrh.org.au

\section{A B S T R A C T}

Introduction: The shortage of residential aged care places is especially acute in rural areas and this results in many older people who live in these areas being forced to leave their home communities to access care in distant communities. This article reports on one aspect of a larger study that explored family and caring community members' experiences when someone they cared for needed to access residential aged care away from their rural communities.

Methods: This qualitative research project, informed by phenomenology, was conducted in rural communities of New South Wales (NSW), Australia. Participants were recruited from media coverage of the proposed research. Indepth interviews were conducted, audiotaped and transcribed. Thematic analysis was undertaken by two researchers independently analysing the themes and then cross-checking these to ensure their strength.

Results: The 21 interviews conducted revealed that inaccessibility of residential aged care places caused many to experience loss, loneliness and a sense of social disconnectedness. The affected rural older person is exiled from their home community only to return to be buried. There are implications for the family and the rural community who are distanced by kilometres, transport and finances and, more significantly, by the emotional ties that bind families, friends and communities.

Conclusion: The participants whose experiences were explored in this article described a sense of being in exile when residential aged care services are inaccessible in their local communities. The sense of exile is felt not only by the person moving away but also by their family, friends and neighbours. For this reason, rural residential aged care service delivery should be based on the identified needs of the older person and those who love and care for them.

Key words: ageing, Australia, carers, disconnectedness, older people, rurality, service provision. 


\section{Introduction}

According to the Australian government ${ }^{1}$, the greatest aged population growth is in non-metropolitan areas and this trend is predicted to increase. The disproportionate increase of older people compared with younger people in rural communities is due to a greater number of younger people leaving rural communities for study and employment purposes ${ }^{1}$. The older population is likely to choose to remain where they have lived for many decades ${ }^{1}$. The current shortage of residential aged care places is impacting most heavily on residents in rural rather than urban Australia and is predicted to grow exponentially resulting in an estimated shortfall of 280000 aged care places in Australia by $2050^{2}$.

The ageing of the rural and remote population has implications for service delivery, policy-makers and the Australian community as a whole. Crombie et al contend that the effects of ageing will have far-reaching impacts for 'the creativity of government, health professionals and local communities to provide the most appropriate models of care to older people ${ }^{3}$. Yet appropriate services for rural aged care are not solely dependent on these entities. Rural older persons themselves and those who love and care for them are a source of information regarding possible solutions which, with few exceptions, have rarely been considered in the literature.

One such solution is a case management approach where one skilled health worker is assigned to progress through service provision with the older person and their family. This model takes into account the idiosyncrasies and wishes of the individual and their family and then oversees the provision of those services. This can address unemployment levels in rural communities by skilling existing members of the rural community to be case managers. Examples of such a model are found in the studies of Farmer et $\mathrm{al}^{4}$ (rural Scotland), Goins et $\mathrm{al}^{5}$ (rural USA) and McCann et $\mathrm{al}^{6}$ (rural Northern Ireland).
Ageing in rural and remote areas of Australia has particular challenges. The National Rural Health Alliance and Aged and Community Services Australia contend that issues relating to ageing in rural Australia need urgent attention ${ }^{7}$. Crombie et al concur and argue that the issues around ageing in rural areas are 'practice issues' focusing on service delivery, workforce shortages and workforce education ${ }^{3}$. The Australian Institute of Health and Welfare maintain that difficulties relating to distance and isolation are exacerbated by the extreme diversity of an aged population that is increasing at a disproportionate rate compared with that of the younger population ${ }^{8}$.

This article reports on a subset of findings (as yet unpublished) from a qualitative research study conducted in rural New South Wales (NSW) in 2010 by the authors. The larger study that informs this article explored the experiences of family and caring community members when someone significant to them was forced to access residential aged care away from their rural communities. For many participants this resulted in a sense that they and their loved ones felt as if they were living in exile, the theme reported on in this article.

\section{Methods}

\section{Research context}

This article focuses on the experiences of older people aged over 70 years and their families in rural and remote areas of NSW - specifically, those who experienced the impact of inaccessible, residential aged care services. The 21 participants were relatives or carers of older people in residential aged care; they provided an indirect, or secondperson perspective of the experience of the older person accessing the service. A qualitative approach, in particular a phenomenological paradigm, enabled participants to share their stories during indepth interviews which were audiotaped and transcribed verbatim. Each participant was recognised as a unique person rather than just a source of 
data. The participants' stories were essential to this project and their experiences are accepted as both valid and valuable.

Residents in residential aged care are, by definition, in a dependent relationship with carers which makes them vulnerable and therefore unlikely to speak out against a system on which they depend for their survival. To interview residents in aged care facilities and then leave them without ongoing emotional support was considered by the researchers to be unethical as research clearly indicates the older person's strong preference for living at home and in their own community ${ }^{9-12}$. For these reasons the participants whose experiences are reported in this article are all family or caring community members of those in residential aged care. Participants were selected from rural and remote communities in NSW. Someone significant to them had experienced moving away from their rural community in order to access residential aged care.

Participants were recruited with the assistance of Charles Sturt University Media who issued a press release through rural and remote radio and the print media inviting potential participants to contact the research team. There was also a snowballing effect where participants advised others of the study.

\section{Data collection}

Data were collected during indepth interviews which lasted, on average, one hour. Interviews were conversational in style with non-directional prompts used to encourage communication but not to influence responses. The participants drove the interviews with the interviewers taking cues from them about issues and concerns that they wished to share. Data collection and analysis occurred concurrently and interviews were ceased when no new themes emerged from the data.

\section{Data analysis}

Audiotapes were transcribed verbatim by an experienced transcriber. Meaning then emerged from thematic analysis of the transcribed interviews using a phenomenological analytical approach in keeping with that described by Polit and Beck ${ }^{13}$. Themes were identified and reflected upon with interpretations offered to participants for checking and by cross-analysis with members of the research team. Only those themes agreed to by consensus with the participants and research team members were included in the findings. As anticipated, the participants' stories wove a rich tapestry of meaning, providing images that articulated what it meant to be a loved one or carer for an elderly person, a member of a rural community, needing residential aged care that was not accessible in their local community.

\section{Ethics approval}

Human ethics approval was obtained from Charles Sturt University Institutional Ethics Committee prior to the commencement of the qualitative research study (protocol number 2010/034). Ethical considerations meant that only family members and caring community members were actively recruited into the study. It was considered unethical to interview the elderly residents themselves because of the potential to exacerbate their distress.

\section{Results}

In all, three major themes were identified on analysis of the data from the qualitative research study conducted in 2010 (M Bernoth, E Dietsch, C Davies, unpubl. data); these will lead to recommendations being made to policy-makers and rural Australian communities. The three themes included 'in exile', 'brokenness' and 'the battle with a system designed to meet its own needs'. Findings reported in this article relate to the first theme, 'in exile', and its related sub themes of the tyranny of distance, seeking aged care services as a last resort, and 'the nightmare' of going into and remaining 'in exile'.

For participants in this study, their loved ones had moved to residential aged care facilities, a distance of 1-12 hours' driving time from their home rural communities. Most 
transfers were less than 3 hours' driving time from their home community but longer distances were $\mathrm{n}$ ot unheard of:

We've been up three times to see him in the last four weeks, on one or two of those occasions... we'll get up here on a Saturday morning...it's a 12 hour round trip, we drive up, and it's five hours in the car, we usually spend two or three hours with Dad. (Participant 10)

Almost all participants would have preferred to have their loved ones stay in their home rural communities. When this proved to be impossible, due to residential care place shortages, the second preference was for elderly persons to be placed in care close to a family member, but even this option was not always possible:

It was very, very difficult ... we were looking for aged care facilities in Port Macquarie, in Goulburn, in Nowra ... there were no beds available until somebody had passed away [died]. (Participant 12)

Leaving their rural community for residential aged care was never an easy option for either the person needing care or their loved ones. It was always seen as a last resort:

I've been sort of Dad's primary carer since Mum passed away and that was just, we didn't want to do that. But the other option was, well, what is the other option? We were running out of options. (Participant 12)

Carers described the nightmare that was the uprooting journey to the place where their loved one could receive residential aged care. In the two scenarios below, participants said that, on discharge from hospital, the closest residential care their parents could access was over an hour away from their homes:

It was very upsetting because she was just so bewildered and was leaving the hospital; normally when you leave hospital you go home. But her head was in such a twist and she knew she was leaving hospital but she wasn't going home but she didn't know where home was, and she was on this great big ride in the country to somewhere ... she cried and cried the whole way. (Participant 7)

[My husband, their son] had to drive them out ... which I think was tough and I think it wrenched at [his] heart because I think every - probably 15 minutes - driving out of town [Dad] was saying, 'Why can't I go home, why can't I go home, where are you taking me, I need to go home'. Now, because they went directly from the hospital to [nursing home] they never, ever got to go back to their home, so they actually went out of the house in an ambulance in a trauma, they didn't pack anything, so when you walked back into that home, there were still toothbrushes sitting with toothpaste on them... There was still a hairbrush, there was still half a meal, they had left like that, and they never returned. (Participant 13)

Other carers described the logistics of having to change their father's incontinence pad on their six-hour journey to access residential care:

He was in Kimbies ... we were faced with a five-and-a-half to six hour trip ... What we discovered is that there's nowhere, like, you have baby change rooms at some facilities. We couldn't change him anywhere at a public toilet or McDonalds, because ... you've got exposure problems and we couldn't go into a babies' change room for example ... it was just impossible. (Participants 1 \& 2)

We did ask about ambulance transport for him because he'd been ill, but we were assured he was fit to travel. (Participants 1 \& 2)

In the scenario described above, this man had been discharged from hospital, was still acutely ill and in excruciating pain. His wife of over 50 years was too frail to accompany him on the journey to the aged care facility. This man died 2 weeks later of lung cancer that had been undiagnosed at the hospital where he had been an inpatient prior to his transfer to residential aged care. He died alone, never seeing his life partner again. 
To access residential aged care, many loved ones of the participants had to leave their rural communities and become socially disconnected from everyone they had ever known and loved:

Dad's lived [here] all his life pretty well, all his working life. He moved here ... when he was chasing Mum in the war. When he came back from the war in 1945 he settled here ... and married Mum and has lived here ever since ... access to family we feel is very, very important. (Participant 12)

So [parents-in-law] were doing very well as aged people they were ... almost $80 \ldots$...elf-sufficient, very proud about their independence, very secure in their set roles and in their set activities and their set geography. They had been in their home that they had had the babies in and raised them and that home had been built out of bricks that had been personally made by their grandfather and father, so we're looking at four generations roughly. (Participant 13)

The sense of social disconnectedness was exacerbated by distance. Many partners, family and community members spoke of their distress in not being able to visit the person they loved in residential aged care:

An elderly person would have a couple of [hundred] kilometres round trip. There's no public transport out of town. (Participant 5)

Availability of residential aged care in rural areas for a single person is very difficult but, for a married couple, it is nearly impossible:

In the case of a married couple, there wasn't a single facility in [regional city] anywhere that, even if they had room, could cater for a married couple. So in the best scenario they would be split: two rooms available at [name of facility], one in one facility, one in another facility approximately half a kilometre apart. (Participant 13)
The care received at residential facilities was varied. A very small number of participants reported positively about the care of their loved ones:

It was a big, big nursing home ... but she got excellent care there. (Participant 3)

And since that time, it's been fantastic, absolutely fantastic. Like to get into the care was great [name of facility], I can't speak highly enough of it. (Participant 12)

Not all reports of residential aged care were positive. Some spoke of poor quality or non-existent care:

That's what I found really disturbing, every time we'd take him back in there, it didn't matter what time ... there was always staff sitting in their office. I think five or six people I counted in there ... it didn't matter when I went ... And I used to think 'This, aged care - this isn't care'. I don't know where the term came from but this isn't care, and I was really annoyed with them. It's not appropriate for staff to sit in large groups like that, without having people on the floor. (Participant 10)

Others drew attention to the residential aged care facility architecture being counter-therapeutic:

One of the cruellest pieces of architecture I've ever seen ... their whole dementia unit overlooks the car park and the main entrance, with big windows ... and what do they see all day - people coming and going in their cars; they see their families coming and going and I think that is so cruel. For family members walking in and out, you feel bad enough, as it is without your relative [who is] probably standing at the window thinking I want to come with you yeah, absolutely the cruellest architecture. (Participant 11)

Attempts to escape demonstrate the misery and desperation that some residents and family members were experiencing:

Then there came a time when he worked out that if he was strapped into a chair ... he could get down onto his hands 


\begin{abstract}
and knees and he could crawl across the floor, so [we] got several calls saying 'Your father's crawled across the floor with a chair strapped on his back trying to escape the facility'. Now, that was probably quite a healthy thing for [Dad], he wasn't suffering psychologically I don't think, because he was doing something about his plight but you can only imagine what it's going to do to [my husband]...that was like the height of putting his father in jail and chaining him to the wall. (Participant 13)
\end{abstract}

Another day, Dad had escaped. This time he took the flyscreen off his room window and put a chair over into the garden and climbed over the fence, and went down through the bush and came up the other side. (Participant 10)

The primary cost was by far the emotional feelings of loss and isolation but some participants also spoke of the high financial price their loved one had paid to be able to live 'in exile' in residential aged care:

He's a self-funded retiree who's paid a $\$ 400,000$ bond to be there, and they give them two dead frankfurts and a blob of sauce or two party pies for dinner. It's pathetic. (Participant 11)

And it was extremely expensive, like \$2500-\$3000 per week. (Participant 12)

There were also financial costs for those visiting residents in distant residential aged care facilities:

When their family comes to visit, their family are regarded as tourists. They've got to pay top dollar at motels; there's no accommodation. (Participants $1 \& 2$ )

There was no return for those translocated from their rural home communities to access care, except to be buried, following what many participants believed was a hastened death:

They don't come back, they die in care ... and they don't want to be there. They don't want to die in care ... I think they hasten their deaths by removing them from their environment ... they go away now, they go away - they die and they come back to be buried. (Participant 4)

People are here, lived here for 80 odd years - picked up taken away from their environment - placed into a strange environment and they would never last very long after that. (Participant 5)

\section{Discussion}

In keeping with the phenomenological philosophy and methodology that informed this study, very careful consideration was given to the essence of the experiences being shared by participants. It was concluded by the research team and confirmed by participants that the core of the experiences being described by them was that the person they loved and cared for had been sent into exile to access the residential aged care they so desperately needed.

Exile has been defined as the 'prolonged, usually enforced, absence from one's country' and country has been defined as 'an area distinguished by its people, culture, language, or government ${ }^{14}$. The participants' experiences and the definition of exile are entirely congruent. In this study, while the participants' loved ones requiring residential aged care remained in their country, they had no choice but to leave their friends and relatives and their rural communities to access care.

Participants described how they believed their only option in obtaining aged care for their loved ones was for them to be uprooted from their communities to become totally, socially disconnected from all they knew and loved and forced into exile. They spoke of the care their loved ones in residential aged care facilities received, some of which was good, some non-existent and some poor. Being 'in exile' was so totally isolating that it added to feelings of loss; attempts by their loved ones to escape and return to their own communities were common. Participants shared how a very high price was paid by both themselves and their loved ones to access residential aged care. Feelings of aloneness 
were acute and many believed their loved one died more quickly in exile.

Maintaining social contact and connection with their community is seen as an important social issue for older people $^{15}$. Social connectedness is based on relationships with family, friends and community ${ }^{16}$, and the participants in this study all described a strong sense of social connectedness between the older person and their family, friends and rural communities, prior to their needing residential aged care. Buckley and McCarthy state that little is known about social connectedness and the meaning it has for an older person although they contend that the more social ties an older person has, the less socially isolated they feel ${ }^{16}$. This sense of connectedness to community is usually strong for older persons living in a rural area, making them potentially more vulnerable if they have to move from familiar settings to access residential aged care. Disconnectedness also affects families and carers who are constantly negotiating their ability to fulfil their roles as carers and supporters of the older person ${ }^{17}$.

Emotional loneliness and social isolation have been identified as interrelated stressors for the older person ${ }^{18}$. Social isolation exacerbated by inaccessibility of residential aged care in their rural communities was a source of distress for the participants in this study. Greaves and Rogers-Clark argue that, as people age, their social networks become inevitably reduced and feelings of fear emerge as their dependency on others increases ${ }^{19}$.

The belief that death was hastened for those who were 'exiled' from their family, friends and communities in order to receive residential aged care is in keeping with theories related to attachment, social networks and patterns of social exchange in later life ${ }^{20}$. Fiori et al argue that reciprocal social support is closely tied to human functioning, a person's sense of wellbeing and reduced mortality ${ }^{20}$.

\section{Limitations}

This study has a number of limitations, including that it was conducted in rural areas of only one Australian state, that is, NSW. For the reasons outlined, participants did not include those requiring residential aged care services but, rather, family and community members who cared for them. No data were forthcoming or sought as to the experiences of participants accessing aged care assessment services or the role such services played. Future research could address this deficit. To honour the richness of the participants' stories, only the theme, being 'in exile' is explored and this must be viewed as a limitation of the study.

Given the qualitative nature of this research project and the small sample size, it is not possible to generalise the findings but it does alert the reader to the possibility that others may experience similar social disconnectedness, loneliness and desperation when residential aged care is inaccessible to them in their home communities.

\section{Conclusion}

When rural residential aged care places are inaccessible in a person's home community, the sense of exile is felt not only by the person moving away, but also by their family, friends and community. For this reason, rural residential aged care service delivery should be based on the identified needs of the older person and those who love and care for them.

This research project has added another dimension to the demographic data that already exist by providing a forum in which older persons' families or carers living in rural areas shared their experiences of what it was like to have their loved ones move from their home communities to access residential aged care. Sadly, the voices of the older persons themselves remain silent but those who love and care for them have articulated their experiences in order to inform policy makers and service providers about the lived experience of ageing in rural and remote areas of New South Wales, Australia. 


\section{References}

1. Department of Health and Ageing. Report on the audit of Health Workforce in Rural and Regional Australia, April 2008. Canberra, ACT: Commonwealth of Australia, 2008.

2. Cutler H, Chao D, McKibbin R. Caring places: planning for aged care and dementia 2010-2050, Vol 2. Canberra, ACT: Access Economics, 2011.

3. Crombie A, Disler P, Threlkeld G. Ageing in rural areas. In: R Nay, S Garratt (Eds). Older people issues and innovations in care, 3rd edn. Sydney, NSW: Elsevier, 2009; 42-59.

4. Farmer J, Philip L, King G, Farrington J, MacLeod M. Territorial tensions: misaligned management and community perspectives on health services for older people in remote rural areas. Health and Place 2010; 16(2): 275-283.

5. Goins R, Williams K, Carter M, Spencer S, Solovieva T. Perceived barriers to health care access among rural older adults: a qualitative study. Journal of Rural Health 2005; 21(3): 206-213.

6. McCann S, Ryan A, McKenna H. The challenges associated with providing community care for people with complex needs in rural areas: a qualitative study. Health and Social Care in the Community 2005; 13(5): 462-469.

7. National Rural Health Alliance Inc, Aged \& Community Services Australia. Older people and aged care in rural, regional and remote Australia: national policy position. Canberra, ACT: NRHA, Aged \& Community Services Australia, 2005.

8. Australian Institute of Health and Welfare. Rural, regional and remote health: indicators of health status and determinants of health. Rural health series 9, cat no. PHE 97. Canberra, ACT: AIHW, 2007.

9. Gitlin L. Conducting research on home environments: lessons learned and new directions. Gerontologist 2003; 43(5): 628-637.
10. Sabia J. There's no place like home: a hazard model analysis of aging in place among older homeowners in the PSID. Research on Aging 2008; 30(3): 3-35.

11. Tang F, Lee Y. Social support networks and expectations for aging in place and moving. Research on Aging 2011; 33(4): 444-464.

12. $\mathrm{Wu} \mathrm{Z}$, Hart R. Social and health factors associated with support among elderly immigrants in Canada. Research on Aging 2002; 24(4): 391-412.

13. Polit D, Beck CT. Essentials of nursing research: appraising evidence for nursing practice, 7th edn. Philadelphia, PA: Lippincott Williams \& Wilkins, 2010.

14. Anon. Collins paperback dictionary. London: HarperCollins, 1995.

15. Stanley M, Moyle W, Ballantyne A, Jaworski K, Corlis M, Oxlade D et al. 'Nowadays you don't even see your neighbours': loneliness in the everyday lives of older Australians. Health and Social Care in the Community 2010; 18(4): 407-414.

16. Buckley C, McCarthy G. An exploration of social connectedness as perceived by older adults in a long-term care setting in Ireland. Geriatric Nursing 2009; 30(6): 390-396.

17. Bramble M, Moyle W, McAllister M. Seeking connection: family care experiences following long-term dementia care placement. Journal of Clinical Nursing 2009; 18(22): 3118-3125.

18. Routasalo P, Savikko N, Tilvis R, Strandberg T, Pitkälä K. Social contacts and their relationship to loneliness among aged people - a population-based study. Gerontology 2006; 52(3): 181-187.

19. Greaves M, Rogers-Clark C. The experience of socially isolated older people in accessing and navigating the health care system. Australian Journal of Advanced Nursing 2009; 27(2): 5-11.

20. Fiori K, Consedine N, Merz E. Attachment, social network size, and patterns of social exchange in later life. Research on Aging 2011; 33(4): 465-493. 